\title{
Long-Term Behaviour of ETFE-Films
}

\author{
K. Moritz ${ }^{*}$, H. Bögner-Balz ${ }^{* *}$, J. Köhnlein ${ }^{* *}$, F. Goecke*, HP. Beck ${ }^{\dagger}$
}

\footnotetext{
* Taiyo Europe GmbH, Mühlweg 2, 82054 Sauerlach, Germany, e-mail: k.moritz@,taiyoeurope.com, web page: https://taiyo-europe.com/de/

** DEKRA Automobil GmbH, Laboratory for Technical Textiles and Foils, Handwerkstrasse 17, 70565 Stuttgart, Germany, Te.: e-mail: heidrun.boegner-balz@dekra.com, jochen.koehnlein@dekra.com, web page: http://www.dekra.com

* se-cover GmbH, Bahnhofstrasse 28, 83119 Obing, Germany, e-mail: florian.goecke@seele.com web page: https://seele.com/de/

$\dagger$ Ingenieurgruppe Bauen GmbH, Besselstraße 16 - 68219 Mannheim, Germany e-mail: patrick.beck@ingenieurgruppe-bauen.de,web page: https://www.ingenieurgruppe-bauen.de/
}

\begin{abstract}
Transparent and translucent ETFE films have been used as a component in architecture since the early 1980's. As pre-tensioned lightweight surface structures applied in roofs, facades or as a whole building envelope, they resist high wind and snow loads and transfer them into the supporting structure. The films are UV-stable and insensitive to typical environmental influences. Tests on disassembled ETFE foils showed no significant changes in their optical and mechanical properties even after a long period of use. Their lifespan can therefore significantly exceed 25 years.

ETFE foils can be pre-tensioned in several layers (multi chamber systems) stabilized by air pressure between the layers or as single-layer structure by means of mechanical pre-tensioning. With the support of cable structures their span width can be increased significantly.

Since used in many applications as permanent load-bearing component it is important to know the long-term behaviour of these films as precisely as possible. Especially in cases of singlelayer constructions, creep and relaxation effects may reduce the pre-stress in the film significantly. These effects depend, as known, on the temperature the time and the loads, respectively the load history. In this context load history means the duration of loads and the velocities the stresses increase and decrease (loading time, relaxation time), furthermore the load history includes the stress-strain levels as well as the ratio of the stresses in extrusion direction (MD) to the ones in transversal direction (TD) of the film.

This contribution includes the description of creep and relaxation behaviour of ETFE-films on the basis of investigations and evaluations of new tests carried out by the named companies and institutions. It refers to uniaxial and biaxial short-term tests as well as uniaxial creep tests at different load levels that have been started more than 10 years ago and which have been recently evaluated.
\end{abstract}

